\title{
Dialogue between primary and secondary health care providers in a Brazilian hypertensive population
}

\author{
Chislene Pereira Vanelli, MSc ${ }^{1,2,3}$ \\ Mônica Barros Costa, PhD ${ }^{1,2}$ \\ Fernando Antonio Basile Colugnati, PhD ${ }^{1,2}$ \\ Hélady Sanders Pinheiro, PhD ${ }^{1,2}$ \\ Elaine Amaral de Paula, MSc $c^{1,4}$ \\ Christiane Chaves Augusto Leite Simão, PhD ${ }^{1,2}$ \\ Mayra Zanon Casagrande ${ }^{1}$ \\ Katiana Vinha de Sousa ${ }^{1}$ \\ Rogério Baumgratz de Paula, PhD ${ }^{1,2}$
}

1. Núcleo Interdisciplinar de Estudos e Pesquisas em Nefrologia (Niepen), Juiz de Fora (MG), Brasil 2. Faculdade de Medicina da Universidade Federal de juiz de Fora (UFJF), Juiz de Fora, (MG), Brasil 3. Faculdade de Ciências Médicas e da Saúde de Juiz de Fora (SUPREMA), Juiz de Fora, MG, Brasil 4. Hospital Escola da Universidade Federal de Pelotas (HEUFPel), Pelotas, RS, Brasil

http://dx.doi.org/10.1590/1806-9282.64.09.799

\section{SUMMARY}

OBJECTIVE: To describe clinical and epidemiological profiles of patients with hypertension referred to a secondary care unit and to assess the adequacy of the referral criteria.

METHOD: This descriptive transversal study analysed 943 hypertensive patients referred to a secondary healthcare unit from September 2010 to August 2012. Clinical and sociodemographic data as well as data regarding the liaison between secondary and primary care services were collected.

RESULTS: Patients' mean age was 59 \pm 13.1 years, and 61.3\% were female. Sedentary lifestyle, alcohol consumption, and smoking were observed in $80.3 \%, 37.1 \%$, and $18.1 \%$ of the patients, respectively. Uncontrolled blood pressure was observed in $72.5 \%$ of the sample, and $80.1 \%$ of individuals were overweight or obese. There was a high prevalence of dyslipidaemia (73.1\%), cardiovascular disease (97.5\%), and reduced glomerular filtration rate (49.9\%). Thirty-eight percent of patients did not meet the referral criteria, of whom approximately $25 \%$ were not hypertensive.

CONCLUSION: Even in a universal-access healthcare system, poor control of hypertension and high prevalence of obesity and cardiovascular diseases were observed. Inadequate referrals and the presence of clinical complications suggest low efficiency of the assistance provided in primary care and reinforce the need for sharing care with the secondary level.

KEYWORDS: Health services. Delivery of health care. Hypertension. Chronic disease.

\section{INTRODUCTION}

Changes in lifestyle and population aging have led to an increasing prevalence of chronic disorders such as hypertension'. Therefore, health systems must adapt to the magnitude of this challenge, especially in developing countries that face scarcity of resources ${ }^{2}$.
As in other countries, hypertension is highly prevalent in Brazil, affecting approximately $32 \%$ of the adult population ${ }^{3}$. Due to its asymptomatic nature, it is estimated that approximately 50\% of hypertensive patients are unaware of the diagnosis, and among

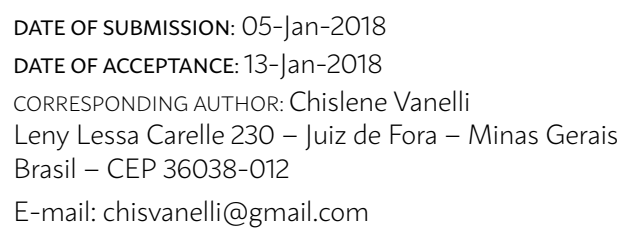


those with an established diagnosis, $65 \%$ do not receive treatment, and only $33 \%$ present adequate blood pressure control ${ }^{3,4}$. Despite an unfavourable socioeconomic profile, the rates of hypertension control in Brazil are close to those of other countries ${ }^{5,6}$, which can be attributed to universal access to the public health system². However, the high rates of morbidity and mortality due to cardiovascular diseases in our country point toward a need to improve the effectiveness of the health system ${ }^{1,7}$.

To meet this challenge, the Brazilian Ministry of Health has proposed the reorganization of the Integrated Networks of Health Services, seeking a more efficient dialogue between primary healthcare (PHC) and secondary healthcare (SHC). In the state of Minas Gerais, this proposal was implemented through the Hiperdia Minas SHC centres. These centres offer an interdisciplinary approach to hypertensive patients with high cardiovascular risk, shared with the $\mathrm{PHC}^{8}$. Given the scarcity of data on the operation of the health system and the data needed for future planning of treatment for severe hypertension, this study aimed to describe the epidemiological profile of patients referred from PHC to the Hiperdia Minas Centre in the city of Juiz de Fora $(\mathrm{CHDM} / \mathrm{JF})$ during the implementation phase of the centre.

\section{METHODS}

\section{Study design and population}

The study was retrospective, cross-sectional, and descriptive. All patients with a diagnosis of hypertension and high cardiovascular risk, on antihypertensive drugs, of both genders, with at least 18 years old, resident in the city of Juiz de Fora, and referred by PHC to the CHDM/JF in the first 2 years of its operation (September 2010 to August 2012) were considered eligible. Juiz de Fora city has 516,247 inhabitants, of whom $99 \%$ reside in the urban area. of 1,190 eligible patients, 247 were excluded: 241 for living in other cities, 5 due to a lack of record of the city of residence, and 1 for being under 18 years old. Thus, 943 individuals were evaluated.

\section{Date setting and data collection}

Three researchers (C.P.V., K.V.S., and M.Z.C.) who were not part of the CHDM/JF collected the data by consultation of electronic medical charts, carried out from November 2012 to May 2014. Data was analysed from February 2013 to August 2014. Demographic, clinical, and laboratory data was collected from the first consultation, and the diagnoses of cardiovascular disease and target-organ lesions (TOL) were collected at the first appointment or up to 3 months after entry into the program. Missing data was included in the category of "not informed/ not available", with differentiated coding for "not applicable" cases.

\section{Epidemiological variables}

The sociodemographic data encompassed age (years), gender, ethnicity (self-declared: Caucasian vs. non-Caucasian), marital status (married/stable partner vs. other), occupation (active vs. not active), family income (in multiples of minimum wage. Brazilian minimum wage references per month were US\$330.00, in 2010; US\$329.27, in January and February 2011; US $\$ 328.31$, from March to December 2011 and US\$332.62, in 2012), education level (illiterate, up to 8 years, 8 to 11 years, $>11$ years), practice of physical activity (direct question: yes vs. no), currently smoking (yes vs. no) and alcohol consumption (yes, in any quantity vs. no).

\section{Clinical data}

We collected systolic blood pressure (SBP) and diastolic blood pressure (DBP) measurements, and the diagnosis of hypertension was based on blood pressure (BP) $\geq 140 / 90 \mathrm{mmHg}$. Blood pressure levels above these values in patients using anti-hypertensive medication were considered to indicate uncontrolled $\mathrm{BP}^{9}$. Obesity and/or overweight were assessed by body mass index (BMI) and abdominal obesity by waist circumference $(>102 \mathrm{~cm}$ in men or $>88 \mathrm{~cm}$ in women) $)^{9}$. The diagnosis of dyslipidaemia was established by one of the following criteria: triglyceride levels $\geq 150 \mathrm{mg} / \mathrm{dl}$; LDL-c $\geq 160 \mathrm{mg} / \mathrm{dl}$; and HDL-c < $40 \mathrm{mg} / \mathrm{dl}$ for men and $<50 \mathrm{mg} / \mathrm{dl}$ for women ${ }^{10}$. The TOL evaluated were hypertensive retinopathy, low estimated glomerular filtration rate (eGFR), and cardiovascular diseases ${ }^{9}$.

Estimated glomerular filtration rate below $60 \mathrm{ml} /$ $\min / 1.73 \mathrm{~m}^{2}$ was considered suggestive of chronic kidney disease ${ }^{11}$. Cardiovascular diseases included previous diagnosis of stroke or coronary disease; peripheral vascular disease, diagnosed by ankle-brachial index lower than 0.9; and presence of diastolic dysfunction of the left ventricle or left ventricular hypertrophy (LVH) on echocardiography. 


\section{System operation}

Compliance with the referral criteria of the patient to the SHC centre was assessed in order to investigate the efficiency of the dialogue between PHC and the CHDM/JF. Referral criteria included refractory hypertension, hypertension associated with TOL, suspicion of secondary arterial hypertension, or high cardiovascular risk. Failures to complete medical records at the SHC service were also recorded.

\section{Ethical considerations}

The study was authorized by the City Health Office of Juiz de Fora, MG and approved by the Human Research Ethics Committee of the University Hospital of the Federal University of Juiz de Fora, under the number 133,399.

\section{Statistical analysis}

Categorical and quantitative variables were analysed descriptively, in strata. The results were presented as mean and standard deviation or median and 25-75 percentiles, according to normality, reviewed by the Kolmogorov-Smirnov test. Numerical variables were compared by Student's t test. For the analysis of the association between the variables, the Pearson's coefficient was used. The data was analysed using SPSS 19.0 software (SPSS Inc., Chicago, USA).

\section{RESULTS}

\section{Sociodemographic data}

Nine hundred forty-three patients were evaluated, with a mean age of $59 \pm 13.0$ years and a predominance of individuals in the 41-60-year age range $(46.8 \%)$, female $(61.3 \%)$, and non-Caucasian (83.9\%). Five hundred forty-five individuals (58.9\%) were married or had a stable partner, $468(49.7 \%)$ were not active professionally, and 308 (71.6\%) had a family income of up to three times the Brazilian minimum wage, with a median of US\$667.5 (US\$54.0 US $\$ 4,268.3)$. Most patients $(75.8 \%$ ) had up to 8 years of education, and 80 individuals (8.5\%) self-declared being illiterate. The majority of the evaluated population was sedentary $(80.3 \%)$, while smoking and alcohol consumption were present in $18.1 \%$ and $31.1 \%$ of the sample, respectively (Table 1).

\section{Clinical data}

Mean SBP and DBP were $151 \pm 28.3 \mathrm{mmHg}$ and
TABLE 1: SOCIODEMOGRAPHIC PARAMETERS AND RISK FACTORS IN HYPERTENSIVE PATIENTS AT FIRST CONSULTATION AT THE HIPERDIA MINAS CENTER, JUIZ DE FORA, BRAZIL, FROM SEPTEMBER 2010 TO AUGUST 2012

\begin{tabular}{|c|c|c|}
\hline \multicolumn{2}{|l|}{ Variable } & \multirow{2}{*}{$\begin{array}{l}\text { Mean } \pm \text { SD / \%* } \\
59 \pm 13.0\end{array}$} \\
\hline Agea & & \\
\hline & $>65$ years old & $33.9(320 / 943)$ \\
\hline \multirow[t]{2}{*}{ Gender } & Female & $61.3(578 / 943)$ \\
\hline & Male & $38.7(365 / 943)$ \\
\hline \multirow[t]{2}{*}{ Ethnicityb } & Caucasian & $16.1(152 / 943)$ \\
\hline & Non-Caucasian & $83.9(791 / 943)$ \\
\hline \multirow[t]{2}{*}{ Marital statusc } & Married/stable partner & $60.2(555 / 922)$ \\
\hline & Other & $39.8(367 / 922)$ \\
\hline \multirow[t]{2}{*}{ Occupationd } & Active & $27.9(181 / 649)$ \\
\hline & Not Active & $72.1(468 / 649)$ \\
\hline \multirow[t]{4}{*}{ Family incomee } & Less than 1 minimum wage & $3.0(13 / 430)$ \\
\hline & $\begin{array}{l}\text { From } 1 \text { to less than } 3 \text { minimum } \\
\text { wages }\end{array}$ & $68.6(295 / 430)$ \\
\hline & $\begin{array}{l}\text { From } 3 \text { to less than } 5 \text { mini- } \\
\text { mum wages }\end{array}$ & $21.4(92 / 430)$ \\
\hline & More than 5 minimum wages & $7.0(30 / 430)$ \\
\hline \multirow[t]{4}{*}{ Education } & Illiterate & $8.5(80 / 937)$ \\
\hline & Up to 8 years & $76.3(715 / 937)$ \\
\hline & From 8 to 11 years & $13.3(125 / 937)$ \\
\hline & Over 11 years & $1.8(17 / 937)$ \\
\hline Sedentary lifestylef & & $80.3(647 / 806)$ \\
\hline Tobaccog & & $18.1(125 / 689)$ \\
\hline Alcoholh & & $31.1(229 / 737)$ \\
\hline \multirow[t]{2}{*}{ Blood pressure } & Controlled (<140/90 mmHg) & $27.5(257 / 936)$ \\
\hline & Uncontrolled & $72.5(679 / 936)$ \\
\hline \multirow[t]{3}{*}{$\mathrm{BMI}\left(\mathrm{kg} / \mathrm{m}^{2}\right) \mathrm{a}$} & Women & $32 \pm 7.1$ \\
\hline & Men & $29 \pm 5.8$ \\
\hline & Total & $31 \pm 6.8$ \\
\hline \multirow{5}{*}{$\begin{array}{l}\text { Nutritional status (BMI, } \\
\mathrm{kg} / \mathrm{m}^{2} \text { ) }\end{array}$} & Underweight & $0.6(06 / 925)$ \\
\hline & Eutrophic & $19.2(178 / 925)$ \\
\hline & Overweight & $31.8(294 / 925)$ \\
\hline & Obese & $48.3(447 / 925)$ \\
\hline & $\begin{array}{l}\text { Above weight } \\
\text { (overweight + obese) }\end{array}$ & $80.1(741 / 925)$ \\
\hline \multirow[t]{3}{*}{ Waist circumference $(\mathrm{cm}) \mathrm{a}$} & Women & $104 \pm 14.0$ \\
\hline & Men & $101 \pm 14.1$ \\
\hline & Total & $103 \pm 14.1$ \\
\hline \multirow[t]{2}{*}{ Abdominal obesity } & Absent & $14.2(119 / 837)$ \\
\hline & Present & $85.8(718 / 837)$ \\
\hline $\begin{array}{l}\text { Total cholesterol } \geq 200 \\
\mathrm{mg} / \mathrm{dl}\end{array}$ & & $49.6(195 / 395)$ \\
\hline Triglycerides $\geq 150$ mg/dl & & $45.0(170 / 378)$ \\
\hline $\mathrm{LDL-c}>100 \mathrm{mg} / \mathrm{dl}$ & & $66.5(222 / 336)$ \\
\hline $\begin{array}{l}\text { HDL-c below reference } \\
\text { valuei }\end{array}$ & & $43.2(161 / 373)$ \\
\hline Dyslipidaemia & & $73.1(274 / 375)$ \\
\hline
\end{tabular}

Abbreviation: BMI, body mass index. ${ }^{~} F o r$ some variables, data were not available for all 943 patients. The number in parenthesis shows the absolute number of individuals over the total available number. a Data are presented as mean + SD or frequency. b Ethnicity: self-declared. c Marital Status: Married includes married or those living with a partner; Others include dic Marital Status: Married includes married or those living with a partner, Others include divorced, widowed, and single. d Occupation: formal employment. e Brazilian minimum wage ( Sedentary lifestyle: no practice of physical activity outside working hours. $\mathbf{g}$ Smoking: cigarettes. h Alcohol. consumption of alcoholic beverages at any dose. i Corrected HDL-c. below $40 \mathrm{mg} /$ $\mathrm{dl}$ for men and below $50 \mathrm{mg} / \mathrm{dl}$ for women. $\mathbf{j}$ The test results were brought by patients to begin treatment at the SHC CHDM/JF program. 
$91 \pm 15.9 \mathrm{mmHg}$, respectively, and 679 subjects $(72.5 \%)$ presented inadequate blood pressure control. Although hypertriglyceridemia was the most frequent lipid disorder (Figure 1), the median value was 138 $[35-3,255] \mathrm{mg} / \mathrm{dL}$. The mean levels of total cholesterol and LDL cholesterol were elevated, and the level of HDL cholesterol reduced. Notably, 681 (72.2\%) patients did not have complete laboratory evaluation of their lipid profile at the time of admission to SHC.

The mean body mass index (BMI) was $31 \pm 6.8 \mathrm{~kg} /$ $\mathrm{m}^{2}$ and higher in women $\left(32 \pm 7.1\right.$ vs $\left.29 \pm 5.8 \mathrm{~kg} / \mathrm{m}^{2}\right)$ $(p<0.001)$. Excess weight was present in 741 individuals $(79.9 \%)$, and abdominal obesity was found in 718 subjects $(85.8 \%)$ (Table 1$)$.

The correlation observed between BP control and BMI classification, education and family income were weak, with coefficient values of $0.13,-0.04$, -0.07 , respectively. On the other hand, the statistical significance between BP control and BMI classification, education and family income were, respectively, <0.001, 0.20, 0.04.

\section{Target-organ lesions}

We found a predominance of CVD, followed by low eGFR. The most prevalent CVD were left ventricular diastolic dysfunction, peripheral vascular disease, and LVH (Tables 2 and 3). Two hundred twenty-four individuals $(23.8 \%)$ were not evaluated in relation to all possible TOL.

\section{System functioning}

With regard to meeting the criteria for referral to the CHDM/JF, 505 patients (53.6\%) were using three or more antihypertensive drugs and 191 (20.3\%) had hypertension associated with prior TOL (stroke and/

TABLE 2: CARDIOVASCULAR IMPAIRMENT UPON ADMISSION TO THE HIPERDIA MINES CENTER, JUIZ DE FORA, BRAZIL, FROM SEPTEMBER 2010 TO AUGUST 2012

\begin{tabular}{l|l} 
Variables & $\%^{*}$ \\
\hline Strokea & $10.0(82 / 822)$ \\
\hline Coronary disease & $15.3(126 / 825)$ \\
\hline Peripheral vascular diseaseb & $58.1(200 / 344)$ \\
\hline Left ventricular diastolic dysfunctionc & $76.1(488 / 641)$ \\
\hline Left ventricular hypertrophyc & $45.6(292 / 641)$ \\
\hline Cardiovascular diseased & $97.5(657 / 674)$ \\
\hline
\end{tabular}

${ }^{*}$ For some variables, data were not available for all 943 patients. The number in parenthesis shows the absolute number of individuals over the total available number. a Stroke: prior history. b Peripheral vascular disease: assessed by the corrected an kle-arm index. c Diastolic left ventricular dysfunction and left ventricular hypertrophy: assessed by echocardiography. $\mathbf{d}$ Cardiovascular disease: showing some cardiovascular changes. or coronary disease). By contrast, 87 individuals (9.2\%) were not taking any anti-hypertensive drug, and 247 (28.9\%) were hypertensive without prior TOL and taking only 1 or 2 antihypertensive drugs, i.e. they did not meet the referral criteria for SHC. Laboratory tests of lipids and renal function were available in only $27.8 \%$ and $45.5 \%$ of the medical charts, respectively. On the other hand, $71.8 \%$ of the charts contained all the minimum standardized information.

\section{DISCUSSION}

In this study, high cardiovascular risk hypertensive patients referred to a SHC centre were predominantly elderly, obese, and sedentary women with dyslipidaemia and uncontrolled blood pressure levels. These characteristics are often found in hypertensive patients followed at the PHC and referred to specialized care. In addition, a high prevalence of TOL was observed.

The low socioeconomic level encountered in this study, a known limiting factor for the treatment of chronic conditions, must be highlighted, as it corroborates the data of Yusuf et al. ${ }^{12}$ who evaluated 154,000 adults with CVD and observed that individuals of low-income countries face many challenges to accessing proper treatment for the disease.

Approximately $80 \%$ of the studied sample had excess weight, especially in the abdomen, consistent with studies showing an association between obesity and hypertension ${ }^{13-15}$. Similarly, in the study of Álvarez-Sala et al. ${ }^{16}, 81.4 \%$ of the hypertensive patients had excess weight, while Efstratopoulos et al. ${ }^{17}$, who assessed 3,589 hypertensive patients, found $46.4 \%$ to be overweight and $35.0 \%$ obese. Epidemiological

TABLE 3: PRESENCE OF TOL IN HYPERTENSIVE INDIVIDUALS UPON ADMISSION TO THE HIPERDIA MINAS CENTER, JUIZ DE FORA, BRAZIL, FROM SEPTEMBER 2010 TO AUGUST 2012

\begin{tabular}{l|l} 
Variables & $\%^{*}$ \\
\hline Hypertensive retinopathya & $1.5(12 / 814)$ \\
\hline Estimated glomerular filtration rate & $49.9(214 / 429)$ \\
\hline $\begin{array}{l}\text { Cardiovascular disease diagnosed after atten- } \\
\text { dance at the SHC }\end{array}$ & $85.6(572 / 668)$ \\
\hline TOL & $75.7(714 / 943)$ \\
\hline Diagnosis before attendance at the SHC & $27.0(193 / 714)$ \\
\hline Diagnosis after attendance at the SHC & $73.0(521 / 716)$ \\
\hline
\end{tabular}

Abbreviations: SHC, secondary health care; TOL, target-organ lesions. *For some variables, data were not available for all 943 patients. The number in parenthesis shows the absolute number of individuals over the total available number. aHypertensive retinopathy: diagnosed at the Hiperdia Minas Center. 


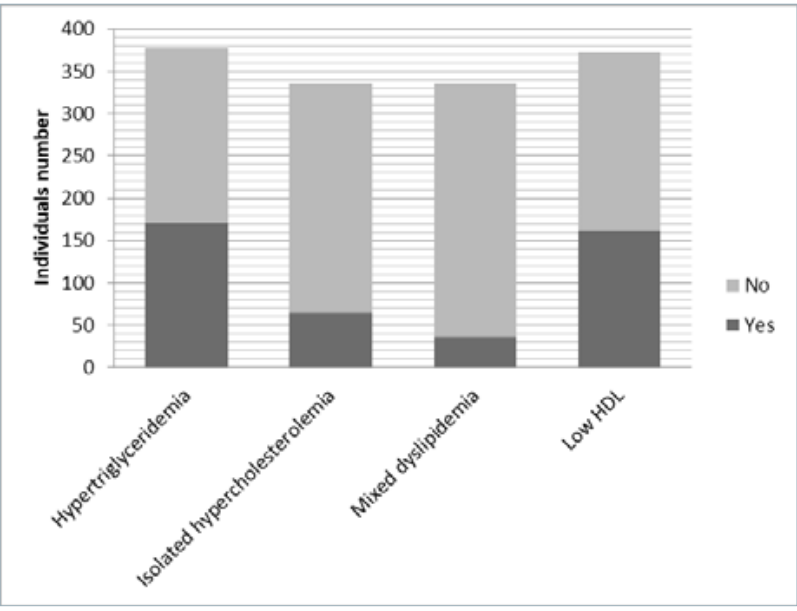

FIGURE 1: Lipid profile of studied population at the admission to SHC.

studies have reported that up to $75 \%$ of the risk for the development of hypertension may be attributed to excess weight ${ }^{18}$. Moreover, an alarming proportion of our study population was sedentary, contrasting with studies such as that by Gregg et al. ${ }^{19}$, who reported a sedentary lifestyle rate of $31.5 \%$ in a population of 3,358 hypertensive American women over 65 years of age.

Even though uncontrolled BP was one criterion for entry into the program, the very high rate of uncontrolled BP we observed is worrying. Inadequate hypertension treatment not only increases cardiovascular risk but also favours evolution to more advanced stages of the disease ${ }^{7}$. Accordingly, in a multicentre study that included 2,649 individuals at high cardiovascular risk treated in PHC, it was found that $60 \%$ of sample had inadequate hypertension control $^{16}$. Despite universal access to the health system, findings of inadequate blood pressure control coupled with sedentary lifestyle, overweight, and obesity at entry into SHC point to a low effectiveness of the management of chronic conditions in $\mathrm{PHC}^{\mathbf{1}, 18-21}$.

Taking into account the characteristics of this population, risk stratification is crucial for referring individuals at high cardiovascular risk to $\mathrm{SHC}^{22}$. However, the high percentage of individuals referred to SHC without assessment of their lipid profile hampers the stratification of cardiovascular risk in the various levels of the healthcare network (HCN). This strategy is essential in SHC to reduce morbidity and mortality in individuals whose cardiovascular risk is often underestimated ${ }^{22,23}$.

In addition, the finding of a high prevalence of
TOL, especially left ventricular diastolic dysfunction and $\mathrm{LVH}$, is compatible with inadequate control of hypertension ${ }^{7,24}$. In parallel, two-thirds of the patients were diagnosed with peripheral vascular disease, a condition associated with a higher risk for coronary disease $^{25}$. Regarding chronic kidney disease, in a 13year follow-up study of 281 patients with severe hypertension, Segura et al. ${ }^{26}$ found that $15 \%$ of patients had reduced eGFR due to hypertensive nephrosclerosis. Other authors, in different populations, have emphasized the close relationship between hypertension and risk for chronic kidney disease ${ }^{27,28}$, which in turn is associated with high cardiovascular risk $^{29}$. In our sample, we found that $50 \%$ of patients had a reduced eGFR. However, this study is not prospective and does not reflect the care at the SHC level, but rather the state of health of hypertensive patients referred from PHC. The higher prevalence of individuals with reduced eGFR observed in this study could be justified by the fact that we evaluated a population with severe hypertension, involving resistant or secondary hypertension and high cardiovascular risk.

The high blood pressure levels and lack of laboratory evaluation of dyslipidaemia in conjunction with high prevalence of obesity and sedentary lifestyle point to the low effectiveness of interventions at the PHC level, suggesting that compliance with clinical guidelines has not received adequate attention in the HCN, resulting in impaired care of patients with hypertension ${ }^{30}$. This weakness in patient care is consistent with a previous study conducted by our group, in which we found that $43 \%$ of PHC physicians do not follow clinical guidelines and/or do not know the criteria for forwarding to SHC services, which can result in inappropriate referral to SHC ${ }^{31}$. In parallel, in the SHC, we observed incompletion of a large number of medical records, suggesting that this tool, indispensable for monitoring and risk stratification of patients with hypertension, also did not receive proper attention from PHC professionals. In this context, the study of Flink et al. ${ }^{32}$ also points to a lack of important information for the proper care of patients with chronic health conditions in the context of the HCN. Moreover, according to Paes et $\mathrm{al}^{33}$, the assessment of health services quality is crucial for adherence to treatment, doctor-patient relationship and appropriateness in the use of services.

The present study presents limitations such as 
lack of basic information in the medical records, which created difficulties in the stratification of cardiovascular risk. Furthermore, the non-inclusion of patients from other cities did not allow the comparison between different PHC services. On the other hand, this study adds information in this field and may be useful for the development of policies to improve healthcare systems.

\section{CONCLUSION}

In conclusion, our study showed that in hypertensive patients referred to SHC, inadequate blood pressure control, a high prevalence of TOL and inadequate referral practices point to the ineffectiveness of treatment and to the weaknesses in the dialogue between the different levels of the HCN. These findings reinforce the importance of improving the $\mathrm{HCN}$ effectiveness in order to decrease morbidity and mortality secondary to inadequate treatment of hypertension.

\section{ACKNOWLEDGEMENTS}

This study was supported by the Fundação de Amparo à Pesquisa do Estado de Minas Gerais (FAPEMIG, APQ 00054-13), Fundação Instituto Mineiro de Ensino e Pesquisa em Nefrologia (IMEPEN), and the Coordenação de Aperfeiçoamento de Pessoal de Nível Superior (CAPES).

\section{RESUMO}

OBJETIVO: Descrever os perfis clínicos e epidemiológicos de pacientes hipertensos encaminhados para uma unidade de atendimento secundário e avaliar a adequação dos critérios de referência.

MÉTODO: Estudo transversal que analisou 943 pacientes hipertensos encaminhados a uma unidade de atenção secundária à saúde de setembro de 2010 a agosto de 2012. Foram coletados dados clínicos e sociodemográficos, bem como dados de interlocução entre os serviços de atenção primária e secundária.

RESULTADOS: A idade média dos pacientes era de $59 \pm$ 13,1 anos e 61,3\% eram do sexo feminino. O estilo de vida sedentário, o consumo de álcool e o tabagismo foram observados em 80,3\%, 31,1\% e 18,1\% dos pacientes, respectivamente. A pressão arterial descontrolada foi observada em 72,5\% da amostra, e 80,1\% dos indivíduos apresentavam excesso de peso. Houve uma alta prevalência de dislipidemia (73,7\%), doença cardiovascular (97,5\%) e taxa de filtração glomerular estimada reduzida (49,9\%). Trinta e oito por cento dos pacientes não atendiam aos critérios de encaminhamento, dos quais aproximadamente 25\% não eram hipertensos.

CONCLUSÃo: Mesmo em um sistema de saúde de acesso universal, observou-se um controle insuficiente da hipertensão e uma alta prevalência de obesidade e doenças cardiovasculares. Encaminhamentos inadequados e a presença de complicações clínicas sugerem uma baixa eficiência da assistência prestada na atenção primária e reforçam a necessidade de compartilhar cuidados com o nível secundário.

PALAVRAS-Chave: Serviços de saúde. Assistência à saúde. Hipertensão. Doença crônica.

\section{REFERENCES}

1. Schmidt MI, Duncan BB, Azevedo e Silva G, Menezes AM, Monteiro CA, Barreto SM, et al. Chronic non-communicable diseases in Brazil: burden and current challenges. Lancet. 2011;377(9781):1949-61.

2. Paim |, Travassos C, Almeida C, Bahia L, Macinko |. The Brazilian health system: history, advances, and challenges. Lancet. 2011;377(9779):1778-97.

3. Sociedade Brasileira de Nefrologia/ Sociedade Brasileira de Cardiologia/ Sociedade Brasileira de Hipertensão. VI diretrizes brasileiras de hipertensão. J Bras Nefrol. 2010;32(Supl. 1):S1-S64.

4. Rosário TM, Scala LCN, França GVA, Pereira MRG, Jardim PCBV. Prevalência, controle e tratamento da hipertensão arterial sistêmica em Nobres, MT. Arq Bras Cardiol. 2009;93(6):672-8.

5. Wang YR, Alexander GC, Stafford RS. Outpatient hypertension treatment, treatment intensification, and control in Western Europe and the United States. Arch Intern Med. 2007;167(2):141-7.

6. Fan AZ, Strasser SM, Zhang X, Fang J, Crawford CG. State socioeconomic indicators and self-reported hypertension among US adults, 2011 behavioral risk factor surveillance system. Prev Chronic Dis. 2015;12:E27.

7. Lewington S, Clarke R, Qizilbash N, Peto R, Collins R; Prospective Studies Collaboration. Age-specific relevance of usual blood pressure to vascular mortality: a meta-analysis of individual data for one million adults in 61 prospective studies. Lancet. 2002;360(9349):1903-13.
8. Vargas I, Mogollón-Pérez AS, Unger JP, da-Silva MR, De Paepe P, Vázquez ML. Regional-based Integrated Healthcare Network policy in Brazil: from formulation to practice. Health Policy Plan. 2015;30(6):705-17.

9. James PA, Oparil S, Carter BL, Cushman WC, Dennison-Himmelfarb C, Handler J, et al. 2014 evidence-based guideline for the management of high blood pressure in adults: report from the panel members appointed to the Eighth Joint National Committee (JNC 8). JAMA. 2014;311(5):507-20.

10. Anderson TI, Grégoire I, Hegele RA, Couture P, Mancini GB, McPherson R, et al. 2012 update of the Canadian Cardiovascular Society guidelines for the diagnosis and treatment of dyslipidemia for the prevention of cardiovascular disease in the adult. Can J Cardiol. 2013;29(2):151-67.

11. Kidney Disease: Improving Global Outcomes (KDIGO) CKD Work Group. KDIGO 2012 clinical practice guideline for the evaluation and management of chronic kidney disease. Kidney Int Suppl. 2013;3(1):1-150.

12. Yusuf S, Islam S, Chow CK, Rangarajan S, Dagenais G, Diaz R, et al. Use of secondary prevention drugs for cardiovascular disease in the community in high-income, middle-income, and low-income countries (the PURE Study): a prospective epidemiological survey. Lancet. 2011;378(9798):1231-43.

13. Kannel WB, Brand N, Skinner || Jr, Dawber TR, McNamara PM. The rela- 
tion of adiposity to blood pressure and development of hypertension. The Framingham study. Ann Intern Med. 1967;67(1):48-59.

14. Wang Y, Wang Q). The prevalence of prehypertension and hypertension among US adults according to the new joint national committee guidelines: new challenges of the old problem. Arch Intern Med. 2004;164(19):2126-34.

15. Chaves G, Brítez N, Maciel V, Klinkhof A, Mereles D. Prevalence of cardiovascular risk factors in an urban ambulatory adult population: AsuRiesgo study, Paraguay. Rev Panam Salud Publica. 2015;38(2):136-43.

16. Alvarez-Sala LA, Suárez C, Mantilla T, Franch J, Ruilope LM, Banegas JR, et al; Grupo PREVENCAT. PREVENCAT study: control of cardiovascular risk in primary care. Med Clin (Barc). 2005;124(11):406-10.

17. Efstratopoulos AD, Voyaki SM, Baltas AA, Vratsistas FA, Kirlas DE, Kontoyannis JT, et al. Prevalence, awareness, treatment and control of hypertension in Hellas, Greece: the Hypertension Study in General Practice in Hellas (HYPERTENSHELL) national study. Am J Hypertens. 2006;19(1):53-60.

18. Garrison RJ, Kannel WB, Stokes / $3^{\text {rd }}$, Castelli WP. Incidence and precursors of hypertension in young adults: the Framingham Offspring Study. Prev Med. 1987;16(2):235-51.

19. Gregg EW, Cauley JA, Stone K, Thompson TJ, Bauer DC, Cummings SR, et al. Relationship of changes in physical activity and mortality among older women. JAMA. 2003;289(18):2379-86.

20. Khader A, Farajallah L, Shahin Y, Hababeh M, Abu-Zayed I, Zachariah R, et al. Hypertension and treatment outcomes in Palestine refugees in United Nations Relief and Works Agency primary health care clinics in Jordan. Trop Med Int Health. 2014;19(10):1276-83.

21. Díaz A, Ferrante D. Trends in prevalence of hypertension in Argentina in the last 25 years: a systematic review of observational studies. Rev Panam Salud Publica. 2015;38(6):496-503.

22. Kotseva K, Wood D, De Backer G, De Bacquer D, Pyörälä K, Keil U; EUROASPIRE Study Group. Cardiovascular prevention guidelines in daily practice: a comparison of EUROASPIRE I, II, and III surveys in eight European countries. Lancet. 2009;373(9667):929-40.

23. De Rivas B, Barrios V, Redón J, Calderón A. Effectiveness of an interventional program to improve blood pressure control in hypertensive patients at high risk for developing heart failure: HEROIC study. I Clin Hypertens (Greenwich). 2010;12(5):335-44.

24. Simone G, Gottdiener JS, Chinali M, Maurer MS. Left ventricular mass predicts heart failure not related to previous myocardial infarction: the Cardiovascular Health Study. Eur Heart J. 2008;29(6):741-7.

25. Hirsch AT, Criqui MH, Treat-lacobson D, Regensteiner JG, Creager MA, Olin JW, et al. Peripheral arterial disease detection, awareness, and treatment in primary care. JAMA. 2001;286(11):1317-24.

26. Segura J, Campo C, Gil P, Roldán C, Vigil L, Rodicio JL, et al. Development of chronic kidney disease and cardiovascular prognosis in essential hypertensive patients. J Am Soc Nephrol. 2004;15(6):1616-22.

27. Young JH, Klag MJ, Muntner P, Whyte JL, Pahor M, Coresh J. Blood pressure and decline in kidney function: findings from the Systolic Hypertension in the Elderly Program (SHEP). J Am Soc Nephrol. 2002;13(11):277682.

28. Mojón A, Ayala DE, Piñeiro L, Otero A, Crespo II, Moyá A, et al. Comparison of ambulatory blood pressure parameters of hypertensive patients with and without chronic kidney disease. Chronobiol Int. 2013;30(12):145-58.

29. Tonelli M, Muntner P, Lloyd A, Manns B], James MT, Klarenbach S, et al. Using proteinuria and estimated glomerular filtration rate to classify risk in patients with chronic kidney disease: a cohort study. Ann Intern Med. 2011;154(1):12-21.

30. Oliveria SA, Lapuerta P, McCarthy BD, L'Italien G], Berlowitz DR, Asch SM. Physician-related barriers to the effective management for uncontrolled hypertension. Arch Intern Med. 2002;162(4):413-20.

31. Paula EA, Simão CCAL, Vanelli CP, Soares BC, Lanna CMM, Costa DMN, et al. Vigilância epidemiológica: o contexto da doença renal crônica na atenção primária à saúde. J Bras Nefrol. 2014;36(3 Suppl 1):117.

32. Flink M, Bergenbrant Glas S, Airosa F, Öhlén G, Barach P, Hansagi H, et al. Patient-centered handovers between hospital and primary health care: an assessment of medical records. Int J Med Inform. 2015;84(5):355-62.

33. Paes NA, Silva CS, Figueiredo TMRMD, Cardoso MAA, Lima JO. Satisfação dos usuários hipertensos com os serviços da rede de atenção primária no Brasil: um estudo de validação. Rev Panam Salud Publica. 2014; 36(2):8793. 